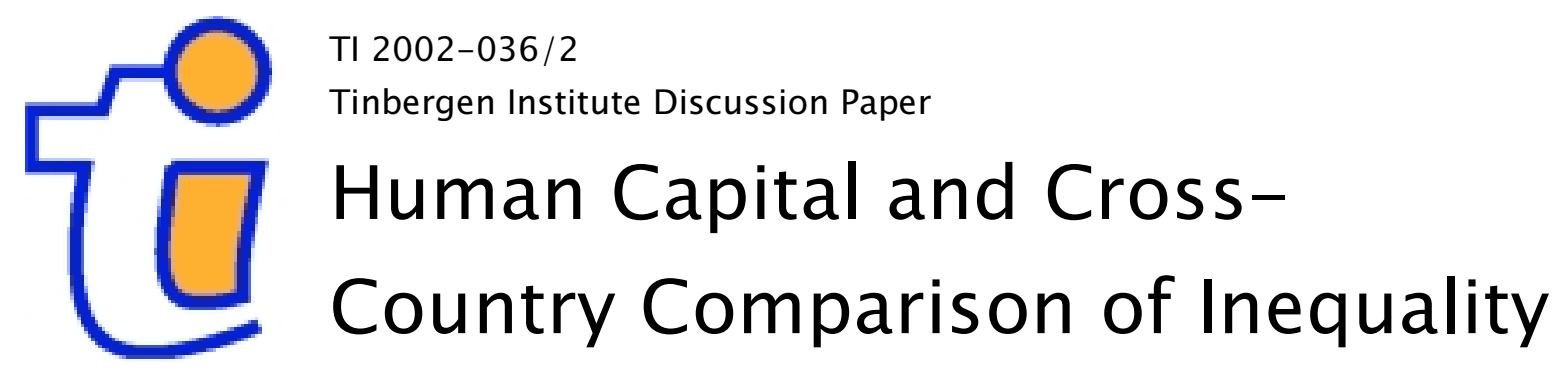

\author{
Jean-Marie Viaene ${ }^{1,2}$ \\ Itzhak Zilcha2,3
}

1 Erasmus University Rotterdam,

2 Tinbergen Institute,

3 The Eitan Berglas School of Economics, Tel Aviv University 
Tinbergen Institute

The Tinbergen Institute is the institute for economic research of the Erasmus Universiteit Rotterdam, Universiteit van Amsterdam and

Vrije Universiteit Amsterdam.

Tinbergen I nstitute Amsterdam

Keizersgracht 482

1017 EG Amsterdam

The Netherlands

Tel.: +31.(0)20.5513500

Fax: $\quad+31 .(0) 20.5513555$

Tinbergen Institute Rotterdam

Burg. Oudlaan 50

3062 PA Rotterdam

The Netherlands

Tel.: $\quad+31 .(0) 10.4088900$

Fax: $\quad+31 .(0) 10.4089031$

Most TI discussion papers can be downloaded at

http://www.tinbergen.nl 


\title{
Human Capital and Cross-Country Comparison of Inequality
}

\author{
Jean-Marie Viaene \\ Erasmus University and Tinbergen Institute Rotterdam
}

Itzhak Zilcha

The Eitan Berglas School of Economics, Tel Aviv University

April 29, 2002

\begin{abstract}
The paper studies the effects of cross-country differences in the production process of human capital on income distribution and growth. Our overlapping generations economy has the following features: (1) consumers are heterogenous with respect to parental human capital and wealth; (2) intergenerational transfers take place via parental education and, public investments in education financed by taxes (possibly, with a level determined by majority voting); (3) due to investment in human capital, which is a factor of production, we have endogenous growth. We explore several types of cross-country variations in the production of human capital, some attributed to 'home-education' and others related to 'public-education', and their effect upon intragenerational income inequality and growth along the equilibrium path. We also indicate how the level of public education affects human capital formation and the conditions leading to poverty traps.
\end{abstract}

JEL classification: D91; E25; H52

Keywords: Human Capital; Income Inequality; Endogenous Growth. 


\section{Introduction}

The well-documented literature on the growth performance of countries has tried to substantiate a negative relationship between inequality and growth. Early tests of this hypothesis by Alesina and Rodrick (1994), Persson and Tabellini (1994) and others report evidence of an inverse relationship, while the more recent empirical findings, for instance, by Barro (2000) and Forbes (2000), suggest that this relationship is, instead, positive . From an empirical point of view this lack of concensus is not surprising as the variations in inequality and growth are too different to obtain robust relations between the two [see Quah (2002)]. While the causality between inequality and growth and the functional form relating them are well-studied issues, two important observations from the data suggest a number of open theoretical questions. First, the data show significant shifts of the distribution of income in the more recent past for various countries [Quah (2002)]. Second, while the Gini coefficients within countries vary little around their mean over time [see, Deininger and Squire (1998)], a high variation in inequality measures is observed across countries. For example, data on US income reveal a Gini coefficient of 0.401 and 0.426 in 1989 and 1994 respectively. For Chile, the corresponding coefficients are 0.573 and 0.565 [see, Tabatabai (1996)]. Therefore, the questions of what determines income inequality in equilibrium and why it differs across countries assume considerable importance. This paper focuses on the process of human capital formation to examine these issues.

We consider an overlapping generations economy which produces a single good using two types of production factors: physical capital and human capital. Due to investments (private and public) in the human capital of the younger generation, the economy exhibits endogenous growth. Each individual lives for three periods, where during the 'youth' period (in which no economic decision is made) education is acquired. Intergenerational transfers in our economy take place via two channels: investments made by parents in educating their own offspring at home and the provision of public education financed by taxing wage incomes. Home education is provided by the close family and 
carried out mainly through parental tutoring, social interaction, learning devices available at home (such as computor and the internet), etc. In this case the human capital of parents and the time they dedicate to tutoring are important factors. Public education includes formal education in schools, public expenditure related to schooling, the 'outside' social interactions and other activities like the media etc. A government has two tasks in our economy : first, in organizing public education and determining its level and, second, in financing it by taxing wage incomes. In most parts of this work we take the level of public education as given; but we demonstrate that this assumption can be relaxed, for example, by using majority voting in determining public investment in education. It is important to note that in our framework the level of public education means the effective educational inputs related to teaching and not the public education expenditures.

It is well established in many studies (by economists and sociologists as well) that education and training of the younger generation play a significant role in shaping the distribution of income and in enhancing growth. In the last decade we observe an increasing awareness by (local and central) government of the importance of education and, consequently, of enhancing investments to promote human capital skills. As the information technology advances and computors are being integrated into the learning technology, there is an increasing technological contribution to the process of learning. However, these technological changes do not affect the formation of human capital similarly in the various countries. We shall distinguish between cross-country technological gaps which affect mostly the 'home-component' of the education process vs. technological differences which affect mainly the 'public-component' of the human capital production.

Our economy generates an endogenously determined intragenerational income distribution where inequality emanates, mainly, from heterogeneity in parents' human capital (due to their role in home education). Regardless of initial conditions, this occurs even if the government is absent from the education process. The contribution of public education is to dampen differences arising from families' human capital and thereby reduce the inequality in the distribution of human capital and income. Put differently, if one compares two countries which are similar in all respects except for the level of 
public education, the country which invests less in public schooling will face higher income inequality along the whole equilibrium path. Moreover, we show that when the level of public education is "low" the economy may converge to a 'poverty trap'; namely, the stock of human capital will decline over time. On the other hand, higher levels of public education will guarantee that the aggregate human capital increases over time. The above claim holds for any given (positive) provision of public schooling and it is only reinforced if this level is determined under majority voting.

In this work we take no explicit stance regarding the causality between inequality and growth. Basically, we point out that the way in which countries enhance human capital matters: If changes, or improvements, occur mainly in the 'home-education' component of human capital formation it results in higher growth while income inequality rises. On the other hand, when the technological improvments occur mainly in the 'public-education' part, then higher growth is accompanied by less income inequality.

There is a widely held belief that the rise in income inequality observed in some OECD countries is driven by the expansion of world trade and the integration of capital markets. In our framework we find that a country which starts with a lower level of human capital, not necessarily less equal, has a better chance to experience more inequality in future dates. In contrast, trade in goods and physical capital mobility, which are based on initial differences in endowments, do not alter the insight regarding income inequality attained under autarky, although they entail intertemporal effects on output and welfare.

The remainder of the paper is organized as follows. The next section examines the literature. Section 3 presents an OLG model with altruistic heterogenous agents facing a certain process of human capital formation. Section 4 studies the cross-country variation in education systems on intragenerational income inequality; namely, systems with and without public education. Section 5 compares countries which differ in the parameters of the production function of human capital. Section 6 considers the case where public provision of education is determined by majority voting. Section 7 considers the causality between inequality and growth. Section 8 studies the inequality-openness relationship when countries differ in initial endowments. Section 9 discusses the robustness of the 
results. To facilitate the reading we relegate all proofs to the Appendix.

\section{Related Literature}

Endogenous growth models have attracted considerable attention in the economic literature of the last two decades. As was demonstrated in various ways these models provide an extremely efficient analytical tool in studying issues related to growth, convergence and income inequality in equilibrium [see, e.g., Loury (1981), Tamura (1991), Glomm and Ravikumar (1992), Fischer and Serra (1996), Fernandez and Rogerson (1998), van Marrewijk (1999), Galor and Moav (2000), Viaene and Zilcha (2002)]. The main emphasis has been on the role played by human capital as an engine for growth [see, e.g., Razin (1973), Lucas (1988), Azariadis and Drazen (1990)].

Human capital formation is a complex process since education, learning and acquisition of knowledge occur in various ways. It depends not only on parents, schools, the 'environment', but also on the existing technologies. Most statistical offices of international organizations compile extensive lists of indicators that describe and compare various scholastic achievements across countries. From the theoretical point of view, economic models have assumed some particular mechanisms describing the accumulation of human capital. Due to tractability reasons, these processes concentrate on a very few parameters [see, e.g., Eckstein and Zilcha (1994), Orazem and Tesfatsion (1997), Hanushek (2002)]. A different approach was used by Eicher (1996), who assumes endogenous absorption of new technologies into the production process.

In our framework the production function for human capital exhibits two important properties. First, individuals from below-average human capital families have a greater return to investment in public schooling than those from above-average families. In addition, the effort, and therefore cost, of acquiring human capital for the younger generation is smaller for societies endowed with relatively higher levels of human capital [see, e.g., Tamura (1991), Fischer and Serra (1996)]. Second, the importance of parental human capital in forming the human capital of a child has been established [see, e.g., Hanushek (1986)]. For example, Glaeser (1994) divides the education's positive effects 
on economic growth into parts, and concludes that children in families with educated parents obtain a better education than children without support. Also, Burnhill et al. (1990) find that parental education influences entry to higher education in Scotland over and above the influence of parental social class. More recently, Lee and Barro (2001) find that family characteristics, such as income and education of parents, enhance student's performance. A reason which is put forward is that parental education elicits more parental involvement (including related private investment) at home.

Income distribution is a key economic issue and its importance is forcing economists and policymakers to improve their understanding of its underlying determinants. Evidence of a rise in income inequality has been observed in a large number of OECD countries. Some believe that social norms are crucial determinants of earnings inequality [e.g., Atkinson (1999), Corneo and Jeanne (2001)]. Others have thoroughly studied the role of human capital accumulation on income distribution in various contexts [see, e.g., Loury (1981), Becker and Tomes (1986), Galor and Zeira (1993), Benabou (1996), Fernandez and Rogerson (1998)] and have shown how various education systems come about. For example, it was established by Glomm and Ravikumar (1992) that majority voting results in a public educational system as long as the income distribution is negatively skewed. Cardak (1999) strenghens this result by considering a voting mechanism where the median preference for education expenditure, rather than median income household, is the decisive voter. The equilibrium we shall consider in Section 6 is an application of the Median-Voter theorem.

\section{The Model}

\subsection{Human Capital Formation}

Consider an overlapping generations economy with a continuum of consumers in each generation, each lives for three periods. During the first period each child is engaged in education/training, but takes no economic decision. Individuals are economically active during the working period which is followed by the retirement period. We assume no 
population growth, hence population is normalized to unity. At the beginning of the 'working period', each parent gives birth to one offspring. Each household is characterized by a family name $\omega \in[0,1]$. Denote by $\Omega=[0,1]$ the set of families in each generation and by $\mu$ the Lebesgue measure on $\Omega$.

Agents are endowed with two units of time in their second period. One unit is inelastically supplied to labor, while the other is allocated between leisure and selfeducating the offspring. Though each family's supply of labor is inelastic, each family's supply of human capital is responsive to relative factor rewards as will be seen later. Consider generation t, denoted $G_{t}$, i.e., all individuals $\omega$ born at the outset of date $t-1$, and let $h_{t}(\omega)$ be the level of human capital of $\omega \in G_{t}$. We assume that the production function for human capital is composed of two components: informal education initiated and provided by parents at home and public education provided by the government by hiring 'teachers', constructing schools etc. The 'home-education' depends on the time allocated by the parents to this purpose, denoted by $e_{t}(\omega)$, and the 'quality of tutoring' represented by the parent's human capital level $h_{t}(\omega)$. The time allocated to public schooling ( i.e., the level of public education) is denoted by $e_{g t}$. The human capital of the teachers determine the 'quality' of 'public education' in the formation of the younger generation's human capital. We assume that for some constants $\beta_{1}>1, \beta_{2}>1, v>0$ and $\eta>0$, the evolution process of a family's human capital is given as follows. For all $\omega \in G_{t+1}$,

$$
h_{t+1}(\omega)=\beta_{1} e_{t}(\omega) h_{t}^{v}(\omega)+\beta_{2} e_{g t} \bar{h}_{t}^{\eta}
$$

where the average human capital of 'teachers', denoted $\bar{h}_{t}$, is the same as the average human capital of generation t. This can be justified if we assume that the individuals engaged in education in each generation, called 'teachers', are chosen randomly from the population of that generation. The parameters $v$ and $\eta$ measure the externalities derived from parents' and society's human capital respectively. The constants $\beta_{1}$ and $\beta_{2}$ represent how efficiently parental and public education contributes to human capital: $\beta_{1}$ is affected by the home environment while $\beta_{2}$ is affected by facilities, the schooling system, size of classes, neighborhood, social interactions, etc. 
The production function for human capital given by (1) exhibits the property that public education dampens the family attributes. As it is common to all, individuals from below-average families have, therefore, a greater return to human capital derived from public schooling than those born to above-average human capital families. In addition, the effort of acquiring human capital is smaller in countries endowed with relatively higher levels of human capital. An important difference between our process of human capital acquisition and most cases discussed in the literature is the representation of the private and the public inputs in the production of human capital via allocation of time. Our approach suggests that the time spent learning, coupled with the human capital of the instructors, and not the expenditures on education, should be the relevant variables in such a process. This is in line with Hanushek (2002) who argues in favor of considering the 'efficiency' in the public education provision rather than 'expenditure' on public education. This distinction is important since in a dynamic framework the cost of financing a particular level of human capital fluctuates with relative factor rewards.

Consider the lifetime income of individual $\omega$, denoted by $y_{t}(\omega)$. Since the human capital of a worker is observable and constitutes the only source of income, it depends on the effective labor supply. Let $w_{t}$ be the wage rate in period $t$ and $\tau_{t}$ is the tax rate on labor income, then

$$
y_{t}(\omega)=w_{t}\left(1-\tau_{t}\right) h_{t}(\omega)
$$

Under the public education regime the taxes on incomes are used to finance education costs of the young generation. Making use of (1) and (2), balanced government budget means:

$$
\int_{\Omega} w_{t} e_{g t} \bar{h}_{t} d \mu(\omega)=\int_{\Omega} \tau_{t} w_{t} h_{t}(\omega) d \mu(\omega)
$$

or equivalently,

$$
e_{g t}=\tau_{t}
$$

that is, the tax rate on labor is equal to the proportion of the economy's effective labor used for public education. ${ }^{1}$

\footnotetext{
${ }^{1}$ Under a decentralized system, namely under a fully private education regime, both $\tau_{t}(\omega)$ and $e_{g t}(\omega)$
} 


\subsection{Equilibrium}

Production in this economy is carried out by competitive firms that produce a single commodity, using effective labor and physical capital. This commodity is both consumed and used as production input. There is a full depreciation of physical capital. The percapita effective human capital in date $t, \overline{h_{t}}$, is an input in the aggregate production process. In particular we take the (per-capita) production function to be:

$$
q_{t}=F\left(k_{t},\left(1-e_{g t}\right) \overline{h_{t}}\right)
$$

where $k_{t}$ is the capital stock and $\left(1-e_{g t}\right) \overline{h_{t}}=\left(1-\tau_{t}\right) \overline{h_{t}}$ is the effective human capital used in the production process. $F(\cdot, \cdot)$ is assumed to exhibit constant returns to scale, it is strictly increasing, concave, continuously differentiable and satisfies $F_{k}(0,(1-$ $\left.\left.\tau_{t}\right) \overline{h_{t}}\right)=\infty, F_{h}\left(k_{t}, 0\right)=\infty, F\left(0,\left(1-\tau_{t}\right) \overline{h_{t}}\right)=F\left(k_{t}, 0\right)=0$.

Given the public education provision, agent $\omega$ at time $t$ maximizes lifetime utility, which depends on consumption, leisure and income of the offspring. Thus:

$$
\max _{e_{t}, s_{t}} u_{t}(\omega)=c_{1 t}(\omega)^{\alpha_{1}} c_{2 t}(\omega)^{\alpha_{2}} y_{t+1}(\omega)^{a_{3}}\left[1-e_{t}(\omega)\right]^{\alpha_{4}}
$$

subject to

$$
\begin{gathered}
c_{1 t}(\omega)=y_{t}(\omega)-s_{t}(\omega) \geq 0 \\
c_{2 t}(\omega)=\left(1+r_{t+1}\right) s_{t}(\omega)
\end{gathered}
$$

where $h_{t+1}(\omega)$ and $y_{t+1}(\omega)$ are given by equations (1) and (2). The $\alpha_{i}^{\prime} s$ are known parameters and $\alpha_{i}>0$ for $i=1,2,3,4 ; c_{1 t}(\omega)$ and $c_{2 t}(\omega)$ denote, respectively, consumption in first and second period of the individual's economically active life; $s_{t}(\omega)$ represents savings; leisure is given by $\left(1-e_{t}(\omega)\right) ;\left(1+r_{t+1}\right)$ is the interest factor at date t. The offspring's income $y_{t+1}(\omega)$ enters parents' preferences directly and represents the motivation for parents' investment in tutoring and formal education expenditure.

are decision variables of each agent, hence the individual's budget constraint on private education is: $\tau_{t}(\omega) w_{t} h_{t}(\omega)=w_{t} e_{g t}(\omega) \bar{h}_{t}$, where the level of teachers' instruction $e_{g t}(\omega)$ is chosen freely while their average human capital is the same as their corresponding generation. 
Given some tax rates $\left(\tau_{t}\right)$, initial human capital distribution $h_{0}(\omega)$ and $k_{0}$, a competitive equilibrium is $\left\{e_{t}(\omega), s_{t}(\omega), k_{t} ; w_{t}, r_{t}\right\}$ which satisfies: For all $t$ and all individuals $\omega \in G_{t},\left\{e_{t}(\omega), s_{t}(\omega)\right\}$ are the optimum to the above problem given $\left\{w_{t}, r_{t}\right\}$. And, the following market clearing conditions hold:

$$
\begin{gathered}
w_{t}=F_{h}\left(k_{t},\left(1-e_{g t}\right) \overline{h_{t}}\right) \\
\left(1+r_{t}\right)=F_{k}\left(k_{t},\left(1-e_{g t}\right) \overline{h_{t}}\right) \\
k_{t+1}=\int_{\Omega} s_{t}(\omega) d \mu(\omega)
\end{gathered}
$$

Equations (8) and (9) are the clearing conditions on factor markets. Condition (10) is a market clearing condition for physical capital, equating the aggregate capital stock at date $t+1$ to the aggregate savings at date $t$.

After substituting the constraints, the first-order conditions that lead to the necessary and sufficient conditions for an optimum are:

$$
\begin{gathered}
\frac{c_{1 t}}{c_{2 t}}=\frac{\alpha_{1}}{\alpha_{2}\left(1+r_{t+1}\right)} \\
\frac{\alpha_{4}}{\left(1-e_{t}(\omega)\right)}=\frac{\beta_{1} \alpha_{3}\left(1-\tau_{t+1}\right) w_{t+1} h_{t}^{v}(\omega)}{y_{t+1}(\omega)}, \quad \text { if } e_{t}(\omega)>0 \\
\geq \quad \text { if } \quad e_{t}(\omega)=0 .
\end{gathered}
$$

From (6), (7) and (11) we obtain:

$$
\begin{gathered}
c_{1 t}(\omega)=\left(\frac{\alpha_{1}}{\alpha_{1}+\alpha_{2}}\right) y_{t}(\omega) \\
s_{t}(\omega)=\left(\frac{\alpha_{2}}{\alpha_{1}+\alpha_{2}}\right) y_{t}(\omega)
\end{gathered}
$$


Equation (12) allocates the unit of non-working time between leisure and the time spent on education by the parents. The latter, $e_{t}(\omega)$, increases with the parents' human capital $h_{t}$ and the wage, net of taxes, at the future date. Equations (12) and (13) establish a negative relationship between the two types of education, that is, public education substitutes for parental tutoring as $\tau_{t+1}$ increases. Hence, for each individual there exists a particular value of the tax rate such that $e_{t}(\omega)=0$. That is, when the marginal utility of leisure is larger than the utility gain obtained from a marginal increase in the human capital of the offspring due to parental tutoring. Consider the families which choose optimal $e_{t}(\omega)=0$ and denote this set of families in generation $t$ by $A_{t} \subset G_{t}=[0,1]$. It is clear that this set includes individuals with low levels of human capital. In fact, inequality holds in condition (13) if,

$$
1-e_{t}(\omega)<\frac{\alpha_{4}}{\beta_{1} \alpha_{3}}\left[\beta_{1} e_{t}(\omega)+\beta_{2} e_{g t} \frac{\bar{h}_{t}^{\eta}}{h_{t}^{v}(\omega)}\right]
$$

Hence, for each individual in $G_{t}$ we obtain $e_{t}(\omega)=0$ and hence, $\omega \in A_{t}$ if ,

$$
h_{t}^{v}(\omega)<\frac{\alpha_{4} \beta_{2} e_{g t}}{\alpha_{3} \beta_{1}} \bar{h}_{t}^{\eta}
$$

Parental and public education being substitutes, inequality (16) shows that the set $A_{t}$ increases as the level of public provision of education $e_{g t}$ increases.

\section{Income Distribution}

The objective of this section is to consider changes in the intragenerational income distribution, in equilibrium, due to variations in the process of human capital formation. Such variations can be attributed to numerous factors but the ones considered here reflect cross-country differences in education systems. Later sections will deal with technological improvements in the human capital formation process and differences in endowments. 
We shall use the relations we derived in the previous section to obtain a useful expression for income at date $t+1, y_{t+1}(\omega)$. To that end we apply (12) and (13) and make use of (1), (2) and (3) to obtain:

$$
y_{t+1}(\omega)=\left(1-\tau_{t+1}\right) w_{t+1} h_{t+1}(\omega)
$$

where,

$$
h_{t+1}(\omega)=\left(\frac{\alpha_{3}}{\alpha_{3}+\alpha_{4}}\right)\left[\beta_{1} h_{t}^{v}(\omega)+\beta_{2} \tau_{t} \bar{h}_{t}^{\eta}\right]
$$

whenever $e_{t}(\omega)>0$, and

$$
h_{t+1}(\omega)=\beta_{2} \tau_{t} \bar{h}_{t}^{\eta} \quad, \quad \text { whenever } \quad e_{t}(\omega)=0
$$

Equations (17)-(19) determine the income at the future date in terms of the net wage at date $t+1$, the parents' human capital, society's level of human capital at date $t$, the current education input $\left(\tau_{t}=e_{g t}\right)$ and the externalities in education. Note that in this framework there is no direct dependence of incomes across generations.

Let $X$ and $Y$ be two random variables with values in a compact interval in $(-\infty, \infty)$ and let $m_{x}$ and $m_{y}$ denote their respective means. Define $\widehat{X}=X / m_{x}$ and $\widehat{Y}=Y / m_{y}$. Denote by $F_{x}$ and $F_{y}$ the cumulative distribution functions of $\widehat{X}$ and $\widehat{Y}$, respectively. Let $[a, b]$ be the smallest interval containing the supports of $\widehat{X}$ and $\widehat{Y}$.

Definition: $F_{x}$ is more equal than $F_{y}$ if $F_{x}$ dominates in the second-degree stochastic dominance $F_{y}$; namely, for all $t \in[a, b], \quad \int_{a}^{t}\left[F_{x}(s)-F_{y}(s)\right] d s \leq 0$.

This definition, due to Atkinson (1970), is equivalent to the requirement that the Lorenz curve corresponding to $X$ is everywhere above that of $Y$. We say that $X$ is more equal than $Y$ if the c.d.f.s' of $\widehat{X}$ and $\widehat{Y}$ satisfy: $\mathrm{F}_{x}$ is more equal than $F_{y}$. 


\subsection{Inequality without Public Education}

Let us consider first our economy without government intervention in the process of human capital formation. Thus, we take $\tau_{t}=0$ for all $\mathrm{t}$. In this case,

$$
y_{t+1}(\omega)=w_{t+1} h_{t+1}(\omega)
$$

From (16) we know that the set $A_{t}$ is empty, and from (12) we obtain that:

$$
e_{t}(\omega)=e^{*}=\frac{\alpha_{3}}{\alpha_{3}+\alpha_{4}} \quad \text { for all } \quad \omega
$$

We see that in the absence of public education the only source of income inequality is the initial distribution of human capital. This is clear from,

$$
y_{t+1}(\omega)=\beta_{1} w_{t+1} e^{*} h_{t}^{\nu}(\omega)
$$

We conclude from these observations that:

Proposition 1 In the absence of public education income inequality (i) declines over time under decreasing returns to parental human capital (i.e., if $\nu<1$ ), (ii) increases over time under increasing returns (i.e., if $\nu>1$ ), and (iii) remains constant over time under constant returns (i.e., if $\nu=1$ ).

Our economy generates, in equilibrium, an intragenerational income distribution whose inequality is endogenously determined by the externality in the home-part of the production of education. Inequality may decrease even in the absence of public schooling. In this context, it is important to note that increasing returns in parents' human capital have been observed in China [see Knight and Shi (1996)]. When $\nu>1$ inequality increases over time and, due to the 'development trap', $h_{t}(\omega)$ goes to zero for some families, since their initial endowment of human capital is too low. More precisely, this occurs for families $\omega$ with, 


$$
h_{0}(\omega)<\left[\frac{\alpha_{3}+\alpha_{4}}{\beta_{1} \alpha_{3}}\right]^{\frac{1}{\nu-1}}
$$

Thus, the economy experiences a segmentation in the evolution of population's human capital. In addition, when the economy operates without government we also find: (a) A change that affects $\beta_{1}$ has no effect on income inequality; (b) Assuming $\nu<1$, an increase in $\nu$ will increase inequality at all dates. Comparing two countries (or, alternatively, considering a technical change in a given country) the above results show that the two types of technical changes are asymmetric with respect to their effect on income inequality. When the process becomes more efficient (i.e., $\beta_{1}$ increases) it affects similarly all families. For example, if computors are used in each household the effect on income distribution is neutral; however, if parental skills play a more important role in the education process inequality will rise. As we shall see later, in the presence of public education, the former result is modified, while the later result is reinforced .

\subsection{Inequality with Public Education}

Now we introduce public education and assume that its level is determined by the government. Currently, we do not choose explicitly the social decision mechanism underlying its determination. The level at date $\mathrm{t}$ is $e_{g t}$ and it is financed by taxing labor income at a fixed rate $\tau_{t}\left(=e_{g t}\right)$. In the sequel we shall assume that $v \leq 1$ and that $\eta \leq 1$ and, to simplify our analysis, we also assume that $v \leq \eta$. Does public education reduces inequality in equilibrium?

Proposition 2 In the above economy let $h_{0}(\omega)$ be any initial human capital distribution. Increasing the provision of public education results in a more equal intragenerational income distribution in each date.

This result may not be surprising since public education in our framework dampens family attributes: it is provided equally to all young individuals (of the same generation), while it is financed by a flat tax rate on wage income. However, its importance 
lies in the fact that it is proved in equilibrium and that it holds in all future periods. In addition, if one compares two countries which are similar in all respects except for the level of public education, the country which invests less in public schooling will face a higher inequality along the equilibrium path.

Let us consider now the variation over time of inequality. We show that if the tax rate remains fixed intragenerational income inequality declines over time.

Proposition 3 If the same tax rate applies to all levels of income and remains fixed over time, then income inequality declines; namely, income inequality at date $t+1$ is smaller than the inequality at date $t$.

This Proposition illustrates the basic property of public education in our framework; namely, its role in smoothing family attributes. Thus, when human capital formation is characterized by constant or decreasing returns to scale in the family's human capital, the existing socioeconomic disparities are diminished over time in the presence of public education. This role of public education can be illustrated numerically also in the presence of small increasing returns in family's human capital.

\subsection{Under-provision of Public Education and Poverty Trap}

Let us demonstrate now the importance of the level of public education in this economy its long-run human capital stock, and hence to output. In fact, we shall be interested in showing that a higher provision of public education will result along the whole equilibrium path in a positive growth rate of the stock of human capital. However, in the same framework, decreasing the level of public education below a certain threshold may result in a negative growth rate in human capital stock. Hence, our model allows for a poverty trap although we do not assume scale economies [Benhabib and Farmer (1994)].

To simplify our analysis we shall assume, in this section, stationary provision of public education, i.e., $e_{g t}=e_{g}=\tau$ for all t. Let us impose some restrictions on the parameters in our economy in order to demonstrate the following: The level of public education is critical to the positive or negative accumulation of human capital. We shall 
assume in this section only that the parameters in our economy satisfy the following conditions:

(A1) $\frac{\alpha_{3} \beta_{1}}{\alpha_{3}+\alpha_{4}}<1-\xi$, for some $\xi>0$.

(A2) The initial distribution $h_{0}(\omega)$ satisfies: $\overline{h_{0}} \geq 1$.

(A3) $\eta=1$ and $v=1$.

(A4) $\alpha_{4}>\alpha_{3}$.

Proposition 4 Assume that (A1) - (A4) hold. Then:

(a) If $e_{g}$ satisfies:

$$
e_{g} \leq\left[1-\frac{\alpha_{3} \beta_{1}}{\alpha_{3}+\alpha_{4}}\right] \beta_{2}^{-1}
$$

then, along the equilibrium path, the aggregate human capital decreases; namely, $\quad \bar{h}_{t+1}<\overline{h_{t}}$ for $t=0,1,2, \ldots \ldots$

(b) If $e_{g}$ satisfies:

$$
e_{g} \geq\left[1-\frac{\alpha_{3} \beta_{1}}{\alpha_{3}+\alpha_{4}}\right] \frac{\alpha_{3}+\alpha_{4}}{\alpha_{3} \beta_{2}}
$$

then the aggregate human capital increases, namely, $\bar{h}_{t+1}>\overline{h_{t}}$ for all $t$.

This result underlines the important role played by the level of public education. To emphasize this point, let us compare two countries which differ in the provision of public education and their initial distributions of human capital, given that each economy satisfies (A1)-(A4). If $e_{g}$ is chosen to be low in one country, assuming that condition (23) holds, while in the other country it is higher, say condition (24) holds. Then, we obtain a poverty trap in the former country while the latter will have positive rate of growth. Examples of countries with declining human capital exist, as observed from the human capital indicators of Table 2.10 at the World Bank site. 


\section{Comparative Dynamics of Efficiency}

Let us compare now two countries which differ in some parameters of the production process of human capital. It is clear that the same analysis applies to technological progress in the production of human capital within the same economy. We shall study few 'types' of technological variations assuming that the human capital is generated by (1). One way to represent such an improvement is by increasing the 'efficiency' of the education environment, e.g., via the introduction of more sophisticated teaching facilities (computors, for example), reducing class size, better organization of schools, etc. This amounts to increasing the parameters $\beta_{1}$ and/or $\beta_{2}$. Another form of technological improvement in this process is to enhance the effectiveness of the 'teachers' or 'tutors'. For example, better training for teachers, advising parents about tutoring their child, etc. Such an improvement amounts to increasing the parameters $v$ and $\eta$, which bring into expression the effectiveness of the human capital of the parents and/or the 'teachers' in the public education system. We assume that $v \leq 1$ and $\eta \leq 1$ in the sequel, even though this assumption can be relaxed in most cases.

An improvement in one country (vs. the other) in the production of human capital may result in a more efficient home-education or a higher efficiency in the publiceducation, or both. We say that the provision of public education is more efficient if either $\beta_{2} / \beta_{1}$ is larger (without lowering neither $\beta_{1}$ nor $\beta_{2}$ ) or $\eta$ is larger, or both. We say that the private provision of education becomes more efficient if $\beta_{1} / \beta_{2}$ becomes larger (while neither $\beta_{1}$ nor $\beta_{2}$ declines) or $\nu$ becomes larger, or both. It is called neutral in the case where both parameters $\beta_{1}$ and $\beta_{2}$ increase while the ratio $\beta_{2} / \beta_{1}$ remains unchanged. Let us consider now the effect of each type of technological gap in the education process on intragenerational income inequality.

Proposition 5 Consider the above economy. Any improvement in the production process of human capital, given by equation (1), results in:

(a) If public provision of education becomes more efficient the inequality in intragenerational distribution of income declines in all periods. 
(b) If the private provision of education becomes more efficient then inequality increases in all periods.

(c) If the technological improvement is neutral inequality remains unchanged at period 1 but declines for all periods afterwards.

This result demonstrates the asymmetry in technological gap which exists primarily in the public schooling system vs. the one which results mainly from changes in the home environment of learning. The inequality in human capital distribution increases when the private-component of education/learning becomes more efficient because family attributes, i.e., the human capital of parents, are magnified. However, a more efficient public education will reduce inequality in human capital distribution because all children are exposed to teachers with the same average level of human capital: below-average families have a greater return to public schooling than above-average families. When the technological gap in education is neutral, then along the 'better' equilibrium inequality declines, except for the first date, since, after the first period, the effectiveness of the public schooling outweights that of the home education.

\section{Median-Voter Equilibrium}

Our analysis thus far has been carried out under the assumption that the tax rates that finance education, and hence the levels of provision of public education, are exogenously given. This assumption regarding the exogeneity of $\tau_{t}$ is questionable since governments care about the resources invested in public education and their economic implications. Also, due to the heterogeneity of families, the choice of an 'optimal' level of public schooling should represent a political equilibrium. The equilibrium we consider here is an application of the median-voter theorem, widely used in economic theory [see, e.g., Persson and Tabellini (2000), Section 3.3]. Clearly, all our results remain unchanged in this case. To demonstrate that let us show that the results in Proposition 5 are reinforced once the tax rates are chosen according to the median-voter hypothesis. 
Let us substitute the first order conditions (11)-(13) in (5) to obtain an expression for the lifetime utility of agent (family) $\omega \in G_{t}$ in terms of the tax rate $\tau_{t}$ :

$$
U_{t}(\omega)=B_{t}\left[1-\tau_{t}\right]^{\alpha_{1}+\alpha_{2}+\alpha_{3}}\left[\beta_{1} h_{t}^{v}(\omega)+\beta_{2} \tau_{t} \bar{h}_{t}^{\eta}\right]^{\alpha_{3}+\alpha_{4}}
$$

where $B_{t}$ groups parameters and variables given to these individuals at the outset of date t. We also assume that individuals in $G_{t}$ take $\tau_{t+1}$ as given. Since $U_{t}(\omega)$ is concave in $\tau_{t}$ there is a unique maximum for each individual's lifetime utility denoted by $\tau_{t}(\omega)$. It is obtained directly from the first order (necessary and sufficient) condition:

$$
\left(\alpha_{1}+\alpha_{2}+\alpha_{3}+\alpha_{4}\right) \beta_{2} \tau_{t}(\omega) \bar{h}_{t}^{\eta}=\left(\alpha_{3}+\alpha_{4}\right) \beta_{2} \bar{h}_{t}^{\eta}-\left(\alpha_{1}+\alpha_{2}\right) \beta_{1} h_{t}^{v}(\omega)
$$

It is clear that the heterogeneity in voter's optimal policy $\tau_{t}(\omega)$ results from the heterogeneity in their human capital $h_{t}(\omega)$. In particular, the median voter's choice will be:

$$
\tau_{t}(m)=\left[\alpha_{1}+\alpha_{2}+\alpha_{3}+\alpha_{4}\right]^{-1}\left[\left(\alpha_{3}+\alpha_{4}\right)-\left(\alpha_{1}+\alpha_{2}\right) \frac{\beta_{1} h_{t}^{v}(m)}{\beta_{2} \bar{h}_{t}^{\eta}}\right]
$$

Some monotonicity results can be verified from the expression in (26):

$$
\frac{\partial \tau_{t}(m)}{\partial \alpha_{1}}=\frac{\partial \tau_{t}(m)}{\partial \alpha_{2}}<0 \quad \text { and } \quad \frac{\partial \tau_{t}(m)}{\partial \alpha_{3}}=\frac{\partial \tau_{t}(m)}{\partial \alpha_{4}}>0
$$

Also,

$$
\frac{\partial \tau_{t}(m)}{\partial\left(\frac{\beta_{1}}{\beta_{2}}\right)}<0 \quad \text { and } \quad \frac{\partial \tau_{t}(m)}{\partial\left(\frac{h_{t}^{v}(m)}{\bar{h}_{t}^{\eta}}\right)}<0
$$

Observed cross-country differences in education expenditures can be explained by these partial derivatives. For example, as $h_{t}(m)$ drops relative to $\bar{h}_{t}, \tau_{t}(m)$ rises: A below-average median voter favors a higher tax rate than an above-average median voter. 
Also, an increase in $v$ and $\beta_{1} / \beta_{2}$ [or a decrease in $\eta$ ] imply a lower tax rate for financing education.

It is important to note that majority voting strengthens the results regarding income inequality attained under the assumption that $\tau_{t}$ is exogenously given. To illustrate this point let us refer to Propositions 2 and 5, and consider an increase in $\beta_{1}$. By Proposition 5 income inequality rises as the technological change affects the parental education process. In addition, following this increase in $\beta_{1}$ majority voting implies a lower tax rate $\tau_{t}(m)$ which, according to Proposition 2 , leads to a further increase in inequality.

\section{Endogenous Growth}

In our framework the economy has no other sources of income besides the one generated by the aggregate production in which human and physical capital are used. Thus educational investments are essential to creating growth. Let us consider the growth-inequality relationship issue in our framework and the causality linking them. To that end, we wish to compare two countries which differ in some parameters of the human capital formation process. As in the empirical findings it will turn out that in our model there is no explicit stance on the causality between inequality and growth.

Define the growth factor of aggregate labor as:

$$
\gamma_{t} \equiv \frac{\int_{\Omega} h_{t+1}(\omega) d \mu(\omega)}{\int_{\Omega} h_{t}(\omega) d \mu(\omega)}
$$

Substitution of (18) in (28) gives rise to an alternative expression for $\gamma_{t}$ :

$$
\gamma_{t}=\left(\frac{\alpha_{3}}{\alpha_{3}+\alpha_{4}}\right)\left[\beta_{1} \frac{\int_{\Omega} h_{t}^{v}(\omega) d \mu(\omega)}{\int_{\Omega} h_{t}(\omega) d \mu(\omega)}+\beta_{2} \tau_{t} \bar{h}_{t}^{\eta-1}\right]
$$

Remark: When we take the aggregate production function to be of the CobbDouglas type and assume that $\eta=1$ and $v=1$, then by direct computation it can be shown that the labor growth factor $\gamma_{t}$ coincides with the long run economic growth, regardless of the initial conditions. 
Let us consider first the effect that a technological change in the production of human capital will have on output in equilibrium. Consider (1) and note that we call the first term on the RHS, $\beta_{1} e_{t}(\omega) h_{t}^{v}(\omega)$, the home-component, and the second term, $\beta_{2} e_{g t} \bar{h}_{t}^{\eta}$, the public-component. An improvement in the production of human capital which makes either the public provision more efficient or the private provision more efficient will result in higher output at all dates. Any improvement, either in the public-component or the home-component, will imply higher human capital stock as of period 1 and on. Since, the initial capital stock is given this will increase the output in date 1 and, hence, the aggregate savings in this period. Thus the output in date 2 will be higher and hence the capital stock to be used as well. Does a technological progress, which results in higher growth, also mean less inequality? Let us combine our results to obtain:

Proposition 6 Consider some technological differences in the production process of human capital (1).

(a) If the technological gap occurs in the home-component, hence either $\beta_{1}$ is higher or $v$ is higher (or both), it results in higher growth coupled with higher income inequality in all dates.

(b) When the technological gap occurs in the public-component, hence either $\beta_{2}$ is higher or $\eta$ is higher (or both), it results in higher growth accompanied by less inequality.

The proof of this result follows directly from Proposition 5 and it is omitted. Consider, for example, the computor-information revolution as a technological improvement in enhancing knowledge, then we ask whether the the home-component benefits more than the public-component in the process of forming human capital. We believe that in most developed countries computors and internet have enhanced the home-education considerably, while schools benefited only in a limited manner. Part (a) may provide some explanation to the recent widespread phenomena (mostly during the last decade) that in most OECD countries economic growth is accompanied by increasing inequality in the distribution of income. 


\section{Openness}

Throughout this paper we have emphasized that our comparative statics analysis applies, equivalently, to two different scenarios: (i) A two-country comparison when parameters regarding the formation of human capital differ, and (ii) a change in the production of human capital that occurs within a given country. In the first scenario one may wonder to what extent our results obtained earlier are robust to free international trade and to capital mobility between the two countries.

Consider, for example, two similar economies which differ only in the initial distributions of human capital: one economy has higher levels of human capital but the measure of inequality in the initial human capital distribution is the same. Can we compare the equilibrium intragenerational income inequality over time in these two economies? The next proposition provides an answer.

Proposition 7 Consider two economies which differ only in their initial human capital distributions, $h_{0}(\omega)$ and $h_{0}^{*}(\omega)$. Assume that $h_{0}^{*}(\omega)>h_{0}(\omega)$ for all $\omega$, but the initial distributions have the same level of inequality. Then, the equilibrium from $h_{0}^{*}(\omega)$ will have less income inequality at all dates $t, t=1,2,3, \ldots$.

This result indicates that the initial distribution of human capital matters, hence a country that starts with higher levels of human capital, not necessarily more equal, has a better chance to maintain less inequality in its future income distributions.

Proposition 7 compares the equilibrium path of two countries in isolation. Let us now introduce international trade and mobility of physical capital between these two economies, keeping labor immobile internationally. These assumptions about trade and factor mobility will guarantee factor price equalization. In this setting, we claim that if initial conditions, such as stocks of human capital or stocks of physical capital, differ then opening markets between these countries will not affect our results regarding income inequality.

Proposition 8 Consider two countries which differ in their initial conditions. Trade 
in goods and physical capital mobility will not alter the results attained earlier regarding income inequality under autarky.

Clearly, openness has a significant impact on wages , rates of interest and total output of the two countries. However, it is not difficult to see, from equations (17)-(19), that in our framework, in the absence of human capital mobility, such variations in the equilibrium factor prices will not affect our results regarding income inequality since labor incomes vary in the same proportion.

The last proposition can be strengthened considerably if we consider the special case where all individuals in all generations choose to invest in their child's education, i.e., that $e_{t}(\omega)>0$ for all $\omega$. Consider two countries which differ in the parameters of the model (including initial conditions). Assume, for simplicity, that only private education exists; namely, there is no role for government in the education process. Again, trade in goods and physical capital mobility will not affect the results concerning income inequality attained under autarky. The main point to notice in verifying this claim is that, since all the sets $A_{t}$ are empty, the variations of the parameters will only change the incomes, in each date, by some multiplicative term which is equal to all $\omega \in G_{t}$. The variation in the human capital distribution [see (18) and (19)] will not affect the inequality in the human capital distribution.

\section{Discussion}

We have studied the cross-country differences in income distribution in an overlappinggenerations economy with heterogenous households. Heterogeneity results from the nondegenerate initial distribution of human capital across individuals. We derive a number of results which provide explanations for observed cross-country differences in income inequality based on variations in processes of human capital formation (which incorporate both parental, or private, education as well as public education). In particular, our results suggest testable hypotheses regarding a cross-country comparison of inequality and : (a) externalities of family's (and society's) human capital; (b) the effective level 
of public education; (c) the efficiency of public schooling and parental tutoring; (d) economic growth; (e) initial conditions, represented here by the initial level and distribution of human capital and physical capital; (f) the international environment, such as trade and physical capital mobility.

Our framework makes some specific assumptions, therefore, it is subject to the issue of robustness. First, the selection of our functional forms was strongly motivated by stylized facts. For example, incorporating parental role in the human capital formation process is justified due to the repeatedly reported evidence that it has an empirical relevance in a large number of countries. Second, in our framework, the role of technological change in the aggregate production function can be ignored since it has no impact on the equilibrium distribution of income. For example, a Hicks-neutral technical change will not vary the inequality in the distribution of human capital, as long as the tax rate that finances public education does not change. Therefore, we consider only cross-country differences in processes describing the human capital formation. Such technological gaps between countries have widened significantly in the last two decades due to the computors-internet revolution, which led to a tremendous proliferation of knowledge. However, the intensity by which such technologies have penetrated developed and developing countries varies tremendously. As we have shown, the effect of such technological change on growth and inequality is ambiguous: it depends on the manner this change affects our process.

Third, our framework assumes that a continuum of skills used in the production of the single final good and does not consider a segmentation of the labor market between skilled and unskilled workers. This heterogeneity of skills allows us to consider issues like shifts of income distributions and the position of the median voter, but not for countryspecific sectoral shocks. Fourth, our theoretical analysis does not depend on the levels of the public provision of education, $\left\{e_{g t}\right\}$ as long as the provision levels are positive. The choice of a certain 'optimal' level of public education requires some social welfare function due to the heterogeneity of the households. For example, we have applied the majority voting criterion to determine this level using the median voter's optimal 
choice. It turns out that majority voting strengthens the results attained under the assumption of exogenously given level of public education. Fifth, it is important to note that introducing direct intergenerational transfers (via physical capital) in our economy will modify some of our results since, in this case, change in factor price ratios affect individuals differently [see Karni and Zilcha (1994), Viaene and Zilcha (2002)]. However, there is an ongoing debate as to the empirical importance of monetary transfers between generations [see Laitner (1997)]. This framework can also be generalized to include an additional redistributive measure by the government, such as social security. In such a case, where intergenerational transfers take place via education and social security, some of our results may vary as well. In contrast, expanding the tax base to include taxation of interest on savings will not alter the results concerning income inequality.

\section{Appendix}

Proof of Proposition 1: In fact we need to consider here the inequality in the distribution of human capital over time. Given the initial human capital distribution $h_{0}(\omega)$, if $\nu<1$ then the distribution $h_{1}(\omega)$ is attained (up to a constant) from $h_{0}(\omega)$ by applying a strictly concave transformation; hence [using Theorem 3.A.5 in Shaked and Shanthikumar (1994)], $h_{1}(\omega)$ is more equally distributed. This process can be continued for all $t=2,3, \ldots$. Now, when $\nu>1, h_{1}(\omega)$ is obtained (up to a constant) from $h_{0}(\omega)$ via a strictly convex function, hence it is less equally distributed (by the above reference).

Proof of Proposition 2: As we see later it is sufficient to prove this result under the assumption that $e_{t}(\omega)>0$ for all $\omega \in G_{t}$. When this is not the case, raising $e_{g t}$ entails higher income for all low income individuals $\omega \in A_{t}$ which only reinforces the claim. Let us consider Eq.(1) for $t=0$. Since $h_{0}(\omega)$ is given, $h_{0}^{v}(\omega)$ and $\bar{h}_{0}$ are fixed. By raising $e_{g 0}$ the distribution of the human capital for generation $1, h_{1}(\omega)$ becomes more equal. This follows from Lemma 2 in Karni and Zilcha (1994). Moreover, we claim from

(18) that the average human capital in generation 1 increases as well. Increasing $e_{g 0}$ will result in higher $h_{1}(\omega)$ for all $\omega$ and higher level of $\bar{h}_{1}$. Moreover, it also implies 
that $h_{1}^{v}(\omega)$ will have a more equal distribution [see, Shaked and Shanthikumar (1994), Theorem 3.A.5].

Now, let us consider $t=1$. Increasing $e_{g 1}$ will imply the following facts: $h_{1}^{v}(\omega)$ becomes more equal and $\beta_{2} e_{g 1} \bar{h}_{1}^{\eta}$ is larger than its value before we increased the levels of public education. Using (18) and the same Lemma as before we obtain that $h_{2}(\omega)$ becomes more equal. This process can be continued for $t=3,4, \ldots .$. , which establishes our claim. Now let us consider the set of families with $e_{t}(\omega)=0$. To simplify our argument assume that initially $e_{g 0}=0$, then as $e_{g 0}$ increases $h_{1}(\omega)$ will be equal or larger than in the private provision case for all $\omega \in G_{1}$, where $\omega \in A_{0}$. Namely, we claim that:

$$
\beta_{2} e_{g 0} \bar{h}_{0}^{\eta} \geq \beta_{1} e_{0}(\omega) h_{0}^{v}(\omega) \quad \text { for all } \omega \in A_{0}
$$

Using equation ( 21) to substitute $e_{0}(\omega)$ and using the upper bound for $h_{0}^{\eta}(\omega)$ from equation (16), we see that this inequality always holds since, by assumption, $v \leq \eta$. This fact certainly reinforces the proof of our earlier case since at the lower tail of the distribution of income we raised and equalized the income for all $\omega \in G_{1}$, where $\omega \in A_{0}$. This process can be continued for all generations.

Proof of Proposition 3: Let us show first that in each generation individuals with higher level of human capital choose at the optimum higher level of time to be allocated for private education of their offspring. To see this let us derive from the first order conditions, using some manipulation, the following equation:

$$
1-\left[1+\frac{\beta_{1} \alpha_{4}}{\alpha_{3}}\right] e_{t}(\omega)=\frac{\alpha_{4} \beta_{2}}{\alpha_{3}} e_{g t} \bar{h}_{t}^{\eta}\left[h_{t}^{-v}(\omega)\right] \quad \text { for } e_{t}(\omega)>0
$$

which demonstrates that higher $h_{t}(\omega)$ implies higher level of $e_{t}(\omega)$. Let us show that such a property generates less equality in the ditribution of $y_{t+1}(\omega)$ compared to that of $y_{t}(\omega)$. It is useful however, to apply (18) for this issue. In fact it represents the period $t+1$ income $y_{t+1}(\omega)$ as a function of the date t income $y_{t}(\omega)$ via the human capital evolution. Define the function $Q: R \rightarrow R$ such that $Q\left[h_{t}(\omega)\right]=h_{t+1}(\omega)$ using (18) whenever $\omega \notin A_{t}$, and when $\omega \in A_{t}$ this function is defined by: $Q\left[h_{t}(\omega)\right]=\beta_{2} e_{g t} \bar{h}_{t}^{\eta}$. As we have indicated earlier [see the proof of Proposition 2], this function is monotone nondecreasing 
and satisfies: $Q(x)>0$ for any $x>0$ and $\frac{Q(x)}{x}$ is decreasing in $x$. Therefore [see, Shaked and Shanthikumar (1994)], the human capital distribution $h_{t+1}(\omega)$ is more equal than the ditribution in date $t, h_{t}(\omega)$. This implies that $y_{t+1}(\omega)$ is more equal than $y_{t}(\omega)$.

Proof of Proposition 4: Consider the inequality (16), which basically defines the set $A_{t}$, using $(18),(19)$ and (A3) we derive:

$$
\bar{h}_{t+1}=\frac{\alpha_{3} \beta_{1}}{\alpha_{3}+\alpha_{4}} \int_{\sim A_{t}} h_{t}(\omega)+\left(1-\mu\left(A_{t}\right)\right) \frac{\alpha_{3} \beta_{2} e_{g}}{\alpha_{3}+\alpha_{4}} \overline{h_{t}}+\mu\left(A_{t}\right) \beta_{2} e_{g} \overline{h_{t}}
$$

Therefore,

$$
\bar{h}_{t+1}<\frac{\alpha_{3} \beta_{1}}{\alpha_{3}+\alpha_{4}} \int h_{t}(\omega)+\frac{\alpha_{3} \beta_{2} e_{g}}{\alpha_{3}+\alpha_{4}} \overline{h_{t}}+\mu\left(A_{t}\right) \beta_{2} e_{g} \overline{h_{t}} \frac{\alpha_{4}}{\alpha_{3}+\alpha_{4}}
$$

Thus to assure that $\bar{h}_{t+1}<\overline{h_{t}}$, we need to show that:

$$
\frac{\alpha_{3}}{\alpha_{3}+\alpha_{4}}\left[\beta_{1}+\beta_{2} e_{g}\left(1+\mu\left(A_{t}\right) \frac{\alpha_{4}}{\alpha_{3}}\right)\right] \leq 1
$$

Thus, if we replace $\mu\left(A_{t}\right)$ by 1 and take $e_{g}$ to satisfy condition (23), then the above inequality holds.

To prove part (b) let us reconsider equation (32) above. It is clear that,

$$
\bar{h}_{t+1}>\frac{\alpha_{3} \beta_{1}}{\alpha_{3}+\alpha_{4}} \int h_{t}(\omega)-\frac{\alpha_{3} \beta_{1}}{\alpha_{3}+\alpha_{4}} \int_{A_{t}} h_{t}(\omega)+\frac{\alpha_{3} \beta_{2} e_{g}}{\alpha_{3}+\alpha_{4}} \overline{h_{t}}+\frac{\alpha_{4}}{\alpha_{3}+\alpha_{4}} \mu\left(A_{t}\right) \beta_{2} e_{g} \overline{h_{t}}
$$

However, using inequality (16) we obtain that $\int_{A_{t}} h_{t}(\omega)<\mu\left(A_{t}\right) \frac{\alpha_{4} \beta_{2} e_{g}}{\alpha_{3} \beta_{1}} \overline{h_{t}}$. Hence,

$$
\bar{h}_{t+1}>\frac{\alpha_{3} \beta_{1}}{\alpha_{3}+\alpha_{4}} \overline{h_{t}}+\frac{\alpha_{3}}{\alpha_{3}+\alpha_{4}} \beta_{2} e_{g} \overline{h_{t}}
$$

Thus, $\bar{h}_{t+1}>\overline{h_{t}}$ holds whenever $\frac{\alpha_{3} \beta_{1}}{\alpha_{3}+\alpha_{4}}+\frac{\alpha_{3}}{\alpha_{3}+\alpha_{4}} \beta_{2} e_{g} \geq 1$. Namely, it holds under condition (24). 
Proof of Proposition 5: Let the initial distribution of human capital $h_{0}(\omega)$ be given. Compare the following two equilibria from the same initial conditions: One with the human capital formation process given by (1) and another with the same process but $\beta_{2}$ is replaced by a larger coefficient $\beta_{2}^{*}>\beta_{2}$. Clearly, we keep $\beta_{1}$ unchanged. Let us rewrite eq. (17) as follows:

$$
\begin{array}{lrl}
y_{t+1}(\omega)=C_{t}\left[h_{t}^{v}(\omega)+\frac{\beta_{2}}{\beta_{1}} e_{g t} \bar{h}_{t}^{\eta}\right] & \text { for all } \omega \notin A_{t} \\
y_{t+1}(\omega)=C_{t}\left[\frac{\beta_{2}}{\beta_{1}} e_{g t} \bar{h}_{t}^{\eta}\right] & \text { for all } \omega \in A_{t} \\
y_{t+1}^{*}(\omega)=C_{t}^{*}\left[h_{t}^{* v}(\omega)+\frac{\beta_{2}^{*}}{\beta_{1}} e_{g t} \bar{h}_{t}^{*}{ }_{t}^{\eta}\right] & \text { for all } \omega \notin A_{t} \\
y_{t+1}^{*}(\omega)=C_{t}^{*}\left[\frac{\beta_{2}^{*}}{\beta_{1}} e_{g t} \bar{h}_{t}^{*}{ }_{t}^{\eta}\right] & \text { for all } \omega \in A_{t}
\end{array}
$$

where $C_{t}$ and $C_{t}^{*}$ are some positive constants. Since $h_{0}(\omega)$ is fixed at date $t=0$ we find [using once again the Lemma from Karni and Zilcha (1994)] that $\frac{\beta_{2}^{*}}{\beta_{1}}>\frac{\beta_{2}}{\beta_{1}}$ imply that $y_{1}^{*}(\omega)$ is more equal to $y_{1}(\omega)$. We also derive that $h_{1}(\omega)$ are lower than $h_{1}^{*}(\omega)$ for all $\omega$ and, hence, $\bar{h}_{1}<\bar{h}_{1}^{*}$. This inequality reinforces the result when $\mu\left(A_{0}\right)>0$. By (18), using the same argument as in the last proof, $h_{1}^{* v}(\omega)$ is more equal than $h_{1}^{v}(\omega)$ and $\frac{\beta_{2}^{*}}{\beta_{1}} e_{g 1} \bar{h}_{1}^{* \eta}>\frac{\beta_{2}}{\beta_{1}} e_{g 1} \bar{h}_{1}^{\eta}$, hence $h_{2}^{*}(\omega)$ is more equal than $h_{2}(\omega)$. This same argument can be continued for all dates $t=3,4,5, \ldots$. Also note that $A_{t} \subset A_{t}^{*}$ (where $A_{t}^{*}$ is the set of families in $G_{t}$ who choose $\left.e_{t}(\omega)=0\right)$ since $\frac{\beta_{2}^{*}}{\beta_{1}} e_{g t} \bar{h}_{t}^{* \eta}>\frac{\beta_{2}}{\beta_{1}} e_{g t} \bar{h}_{t}^{\eta}$ for all t. This only contributes to the more equal distribution of $y_{t+1}^{*}(\omega)$ since the left hand tail has been increased and equalized compared to the $y_{t+1}(\omega)$ case.

To completes the proof of part (a) of this Proposition consider the case where we increase $\eta$. When we increase the value of $\eta$, keeping all other parameters constant, we are basically increasing the second term in (18), $\left[\bar{h}_{0}\right]^{\eta}$, while $\left[h_{0}(\omega)\right]^{v}$ remains unchanged. By Lemma 2 in Karni and Zilcha (1994) we obtain that the distribution of $h_{1}(\omega)$ becomes more equal. Taking into account the families $\omega \in G_{1}$ who belong to $A_{0}$ (i.e., the lower tail of the distribution of income) only reinforces the higher equality since their incomes are uniformly increase to $\beta_{2} e_{g 1} \bar{h}_{0}^{* \eta}$, while for all other $\omega \in G_{1}, \omega \notin A_{0}$ the proportional raise in their income is smaller. This can be continued for $t=2$ as well since it is easy to verify that $\left[\bar{h}_{1}\right]^{\eta}$ increases while $\left[h_{1}(\omega)\right]^{v}$ becomes more equal. Now, this process can be extended to $t=2,3, \ldots$, which complete the proof of part (a).

The proof of part (b) follows from the same types of arguments using the fact 
that if $\beta_{1}<\beta_{1}^{*}$ then $\frac{\beta_{2}}{\beta_{1}}>\frac{\beta_{2}}{\beta_{1}^{*}}$ and, hence, $h_{1}(\omega)$ is more equal than $h_{1}^{*}(\omega)$ and $\bar{h}_{1}>\bar{h}_{1}^{*}$. This process leads, using similar arguments as before, to $y_{t}(\omega)$ more equal than $y_{t}^{*}(\omega)$ for all periods $t$.

Claim: Comparing two economies which differ only in the parameter $v$. The economy with the higher $v$ will have more inequality in the intragenerational income distribution in all periods.

Since the two economies have the same initial distribution of human capital $h_{0}(\omega)$ the process that determines $h_{1}(\omega)$ differs only in the parameter $v$. Denote by $v^{*}<$ $v \leq 1$ the parameters, then it is clear that $\left[h_{0}(\omega)\right]^{v^{*}}$ is more equal than $\left[h_{0}(\omega)\right]^{v}$ since it is attained by a strictly concave transformation [see, Theorem 3.A.5 in Shaked and Shanthikumar (1994)]. Likewise, the human capital distribution $h_{1}^{*}(\omega)$ is more equal than the distribution $h_{1}(\omega)$. This implies that $y_{1}^{*}(\omega)$ is more equal than $y_{1}(\omega)$. Now we can apply the same argument to date 1 : the distribution of $\left[h_{1}^{*}(\omega)\right]^{v^{*}}$ is more equal than that of $\left[h_{1}(\omega)\right]^{v}$, hence, using (18) and the above reference, we derive that the distribution of $\left[h_{2}^{*}(\omega)\right]^{v^{*}}$ is more equal than that of $\left[h_{2}(\omega)\right]^{v}$. This process can be continued for all $\mathrm{t}$.

Consider now the claim in part (c). From (18) we see that inequality in the distribution of $h_{1}(\omega)$ remains unchanged even though all levels of $h_{1}(\omega)$ increase due to this technological improvement. In particular, $\bar{h}_{1}$ increases. Now, since inequality of $h_{1}^{v}(\omega)$ did not vary but the second term in the RHS of (18) has increased due to the higher value of $\bar{h}_{1}$, we obtain more equal distribution of $h_{2}(\omega)$. When $\mu\left(A_{0}\right)>0$ the higher $\bar{h}_{1}$ results in higher income to all $\omega \in G_{1}$ who belong to $A_{0}$, which only reinforces the more equality in $y_{2}^{*}(\omega)$. Now, this argument can be used again at dates $3,4, \ldots$. which completes the proof.

Proof of Proposition 7: Observe the following two equations used in the proof of Proposition 5: $y_{t+1}(\omega)=C_{t}\left[h_{t}^{v}(\omega)+\frac{\beta_{2}}{\beta_{1}} e_{g t} \bar{h}_{t}^{\eta}\right] \quad$ for all $\omega \notin A_{t}$.

$y_{t+1}(\omega)=C_{t}\left[\beta_{2} e_{g t} \bar{h}_{t}^{\eta}\right]$ for all $\omega \in A_{t}$.

Similarly,

$$
\begin{aligned}
& y_{t+1}^{*}(\omega)=C_{t}^{*}\left[h_{t}^{* v}(\omega)+\frac{\beta_{2}}{\beta_{1}} e_{g t} \bar{h}_{t}^{* \eta}\right] \quad \text { for all } \omega \notin A_{t}^{*} . \\
& y_{t+1}^{*}(\omega)=C_{t}^{*}\left[\beta_{2} e_{g t} \bar{h}_{t}^{* \eta}\right] \text { for all } \omega \in A_{t}^{*} .
\end{aligned}
$$


Since $h_{0}$ and $h_{0}^{*}$ are equally distributed, the same holds for $h_{0}^{v}(\omega)$ and $\left[h_{0}^{*}(\omega)\right]^{v}$, since $v \leq 1$. Moreover, since $\bar{h}_{0}<\bar{h}_{0}^{*}$ we obtain that $h_{1}^{*}(\omega)$ is more equal than $h_{1}(\omega)$ [again, see Lemma 2 in Karni and Zilcha (1994)]. It is easy to verify from (18) that $h_{1}(\omega)$ are lower than $h_{1}^{*}(\omega)$ for all $\omega$. Note that since $y_{1}^{*}(\omega)=C_{0}^{*} \beta_{2} e_{g t} \bar{h}_{t}^{* \eta}$ for all $\omega \in A_{0}$ and $y_{1}(\omega)=C_{0} \beta_{2} e_{g t} \bar{h}_{t}^{\eta} \quad$ for all $\omega \in A_{0}^{*}$ and on these sets $y_{1}^{*}(\omega)>y_{1}(\omega)$ the above argument is not affected by the existence of $A_{0}$ and $A_{0}^{*}$ with positive measure. In particular we obtain that $\left[h_{1}^{*}(\omega)\right]^{v}$ is more equal than $\left[h_{1}(\omega)\right]^{v}$ [see Theorem 3.A.5 in Shaked and Shanthikumar (1994)]. Also we have $\left[\bar{h}_{1}\right]^{\eta}<\left[\bar{h}_{1}^{*}\right]^{\eta}$. This implies, using (18), that $h_{2}^{*}(\omega)$ is more equal than $h_{2}(\omega)$. As in our earlier proofs it is easy to see that this process can be continued to generalize this to all periods.

Proof of Proposition 8: Let us use the fact that in our model the inequality in incomes originates from the inequality in human capital distribution, since the same wage rate multiplies $h_{t}(\omega)$ [see equation (17)]. Now, the trade and physical capital flow will result in equal wages and rates of interest in both countries. Moreover, we claim that in such a case there is no effect on the optimal choices of parental investment in their children; namely, that $e_{t}(\omega)$ will not vary. This can be verified directly from (12) and (13), after substituting $y_{t+1}(\omega)$ by (17) : given $h_{t}(\omega), e_{t}(\omega)$ and hence $h_{t+1}(\omega)$ will not vary as we change $r_{t+1}$ and $w_{t+1}$ as well. Thus the human capital accumulation process will not vary and the sets $A_{t}$ as well [see inequality (16)]. Now, consider equations (18) and (19) to verify that the distribution of $h_{t+1}(\omega)$ will not change for $\mathrm{t}=0,1,2, \ldots$

\section{References}

[1] Alesina, A., Rodrick, D., 1994, Distributive politics and economic growth, Quarterly Journal of Economics 109(2), 465-490.

[2] Atkinson, A.B., 1970, On the measurement of inequality, Journal of Economic Theory 2, 244-263.

[3] Atkinson, A.B., 1999, Is rising income inequality inevitable? A critique of the Transatlantic concensus, UNO/WIDER Publication WAL3.

[4] Azariadis, C., Drazen, A., 1990, Threshold externalities in economic development, Quarterly Journal of Economics 105, 501-526. 
[5] Barro, R. J., 2000, Inequality and growth in a panel of countries, Journal of Economic Growth 5, 5-32.

[6] Becker, G.S., Tomes, N., 1986, Human capital and the rise and fall of families, Journal of Labor Economics 4(3), S1-39.

[7] Benabou, R. ,1996, Equity and efficiency in human capital investment: the local connection, Review of Economic Studies 63, 237-264.

[8] Benhabib, J., Farmer, R.E.A., 1994, Indeterminacy and increasing returns, Journal of Economic Theory 63, 19-41.

[9] Burnhill, P., Garner, C., McPherson, A., 1990. Parental education, social class and entry to higher education 1976-86. Journal of the Royal Statistical Association, Series A, 153(2), 233-248.

[10] Cardak, B.A., 1999, Heteregeneous preferences, education expenditures and income distribution, The Economic Record 75 (228), 63-76.

[11] Corneo, G., Jeanne, O., 2001, Status, the distribution of wealth, and growth, The Scandinavian Journal of Economics 103(2), 283-293.

[12] Deininger, K., Squire L., 1998, New ways at looking at old issues: inequality and growth, Journal of Development Economics 57, 259-287.

[13] Eckstein, Z., Zilcha, I, 1994, The effects of compulsory schooling on growth, income distribution and welfare, Journal of Public Economics 54, 339-359.

[14] Eicher, T. S., 1996, Interaction between endogenous human capital and technological change, Review of Economic Studies 63, 127-144.

[15] Fernandez, R., Rogerson, R., 1998, Public education and income distribution: a quantitative dynamic evaluation of education- finance reform, American Economic Review 88(4), 813-833.

[16] Fischer, R.D., Serra, P.J., 1996, Income convergence within and between countries, International Economic Review 37(3), 531-551.

[17] Forbes, K.J., 2000, A reassessment of the relationship between inequality and growth, American Economic Review 90 (4), 865-887.

[18] Galor, O., Moav, O., 2000, Ability biased technological transition, wage inequality and growth, Quaterly Journal of Economics 115, 469-497.

[19] Galor, O., Zeira, J., 1993, Income distribution and macroeconomics, Review of Economic Studies 60, 35-52. 
[20] Glaeser, E.L., 1994, Why does schooling generate economic growth? , Economics Letters 44(3), 333-337.

[21] Glomm, G., Ravikumar, B., 1992, Public versus private investment in human capital: endogenous growth and income inequality, Journal of Political Economy 100, 818-834.

[22] Hanushek, E.A., 1986, The economics of schooling: production and efficiency in public schools, Journal of Economic Literature, XXIV, 1141-1177.

[23] Hanushek, E.A., 2002, Publicly provided education, in: Auerbach, A., Feldstein, M. (eds), Handbook of Public Economics (Amsterdam: North Holland), forthcoming.

[24] Karni, E., Zilcha, I., 1994, Technological progress and income inequality: A model with human capital and bequests, in: Bergstrand J. et.al (eds), The Changing Distribution of Income in an Open US Economy, (Amsterdam: North Holland), 279-297.

[25] Knight, J., Shi, L., 1996, Educational attainment and the rural-urban divide in China, Oxford Bulletin of Economics and Statistics 58(1), 83-117.

[26] Laitner, J., 1997, Intergenerational and interhousehold economic links. In: Rosenzweig, M.R., Stark, O. (eds), Handbook of Population and Family Economics, (Amsterdam: North Holland).

[27] Lee, J.-W., Barro, R.J., 2001, Schooling quality in a cross-section of countries, Economica $68,465-488$.

[28] Loury, G., 1981, Intergenerational transfers and the distribution of earnings, Econometrica 49(4), 843-867.

[29] Lucas, R., 1988, On the mechanics of economic development, Journal of Monetary Economics 22, 3-42.

[30] Marrewijk, C. van, 1999, Capital accumulation, learning and endogenous growth, Oxford Economic Papers 51, 453-475.

[31] Orazem, P., Tesfatsion, L., 1997, Macrodynamic implications of income-transfer policies for human capital investment and school effort, Journal of Economic Growth 2, 305-329.

[32] Persson, T., Tabellini, G., 1994, Is inequality harmful for growth, American Economic Review 84(3), 600-621.

[33] Persson, T., Tabellini, G., 2000 , Political Economics, (Cambridge: MIT Press). 
[34] Shaked, M., Shanthikumar, J.G., 1994, Stochastic Orders and Their Applications , Academic Press Inc.

[35] Quah, D., 2002, Some simple arithmetic on how income inequality and economic growth matter, in: T. S. Eicher, H-W Sinn and S. Turnovsky (Eds.), Growth and Inequality: Issues and Policy Implications (Cambridge: MIT Press), forthcoming.

[36] Razin, A., 1973, Optimum investment in human capital, Review of Economic Studies 40, 455-460.

[37] Tabatabai, H., 1996, Statistics on Poverty and Income Distribution: An ILO Compendium of Data ( Geneva: International Labor Office).

[38] Tamura, R. 1991, Income convergence in an endogenous growth model, Journal of Political Economy 99, 522-540.

[39] Viaene, J.M., Zilcha I., 2002, Capital markets integration, growth and income distribution, European Economic Review 46, 301-327. 